\title{
Auctioning of EU ETS Phase II allowances: how and why?
}

\author{
Cameron Hepburn, Michael Grubb, Karsten Neuhoff, Felix Matthes and \\ Maximilien Tse
}

May 2006

\section{Auctioning in the EU ETS Key Findings}

\section{Auctioning in general:}

- is likely to increase the macroeconomic efficiency of the EU ETS and offers scope to partially address its distributional impacts

- will have negligible competitiveness impacts

- reduces the distortions associated with free allocation and is correspondingly more compatible with EU State Aid legislation

- $\quad$ will have a smaller impact on EU ETS prices than allocation cutbacks without auctioning

- will increase management attention and thus market efficiency

Auctioning may also provide a hedge against projection uncertainties, reduce price volatility, and increase investor stability. The recent EU ETS market collapse is a dramatic manifestation of uncertainty in emission projections. Reserving some allowances for periodic auctions:

- could assist transparency and liquidity;

- offers a potential price cushioning mechanism (as in US transmission auctions), to create a more stable EU ETS market; and

- might facilitate ex-ante agreed target price ranges, thereby increasing predictability for investors

\section{Auctioning poses no significant implementation difficulties}

- $\quad$ either ascending-bid or sealed-bid auctions could be used and based upon extensive experience, for example with securities auctions

- $\quad$ should be open to as wide a group of bidders as possible

- the concerns of small bidders can be addressed, for example through reserves guaranteed at the strike price

For the longer term (post 2012), auctioning could also:

- help protect industrial competitiveness by enabling WTO-compatible border-tax adjustments

- $\quad$ help provide a long-term carbon price signal by recycling revenue into carbon contracts 


\begin{abstract}
The European Directive on the EU ETS allows governments to auction up to $10 \%$ of the allowances issued in Phase II 2008-2012, without constraints specified thereafter. This paper reviews and extends the long-standing debate about auctioning, in which economists have generally supported and industries opposed greater use of auctioning. The paper clarifies the key issues by reviewing six 'traditional' considerations, examines several credible options for auction design, and then proposes some new issues relevant to auctioning. It is concluded that greater auctioning in aggregate need not increase adverse competitiveness impacts, and could in some respects alleviate them, particularly by supporting border-tax adjustments. Auctioning within the $10 \%$ limit might also be used to dampen price volatility during 2008-12 and, in subsequent periods, it offers the prospect of supporting a long-term price signal to aid investor confidence. The former is only possible, however, if Member States are willing to coordinate their decision-making (though not revenue raising) powers in defining and implementing the intended pricing mechanisms.
\end{abstract}

Keywords: EU ETS, auctions, phase II allocations, windfall profits,

\footnotetext{
* Thanks to Billy Pizer, Paul Klemperer and two anonymous referees for helpful comments. E-mail address: cameron.hepburn@economics.ox.ac.uk.
} 


\section{Introduction}

Whether governments could or should sell emission allowances, instead of giving them out for free, was one of the most hotly contested aspects of negotiating the original EU ETS Directive. It resulted in the compromise - after determined intervention by the European Parliament to raise the threshold - that governments could auction up to 5\% of allowances in Phase I and up to 10\% in Phase II (the Kyoto first period of 2008-12).

This compromise reflects two empirical facts about auctioning. The first is that economists almost uniformly recommend more auctioning. The second is that business tends to oppose it. The result is that despite all the academic recommendations, auctioning in emission trading systems is the exception rather than the rule. ${ }^{1}$ In Phase I, only four out of 25 Member States used auctions at all, and in only one case were auctions fully employed to the $5 \%$ limit. $^{2}$ This contrasts sharply with, for example, the willingness of European governments to auction licences for the European "thirdgeneration" (3G) mobile telecommunications licences, where auctions raised many billions of Euros. ${ }^{3}$ The difference in approach can largely be explained by three factors. First, emissions trading imposes costs on other sectors, producing strong lobbying by incumbents in these markets, whereas costs to other sectors by pricing the $3 \mathrm{G}$ spectrum were much smaller and less obvious. Second, emissions trading may affect national competitiveness in some export sectors. In contrast, competitiveness fears did not arise with the $3 \mathrm{G}$ auctions because international trade in spectrum licences (and downstream sectors) is obviously rather limited. Third, telecommunications is a fast-growing industry, where many powerful players were non-incumbents without the right to grandfathered allowances (Cramton and Kerr, 2002).

However, the political dynamics relevant to emissions allowance auctions may be changing. The great majority of participants in Phase I (as measured by turnover or emissions) are making substantial profits from the system of free allocations, as

\footnotetext{
${ }^{1}$ The U.S. government auctions only $2.8 \%$ of allowances under its $\mathrm{SO}_{2}$ program (McLean, 1997).

${ }^{2}$ Denmark auctioned $5 \%$ and used the revenue to purchase JI/CDM credits, Hungary auctioned $2.4 \%$, Lithuania auctioned $1.5 \%$, and Ireland auctioned $0.75 \%$, with European-wide eligibility, to cover the administrative costs of the scheme.

${ }^{3}$ In the year 2000, the UK auction raised $€ 39$ billion (Klemperer, 2004) and the German auction almost $€ 100$ billion.
} 
economists had predicted. Additionally, there are now potential legal pressures arising from state aid considerations as a consequence of these profits (see Johnston, this Issue). These considerations may increase the appeal of auctions. In this context, we re-examine the issues and arguments for and against auctioning, and also introduce some new considerations as follows:

Section 2 reviews six 'traditional' arguments concerning EU allowance auctions;

Section 3 considers how EU ETS auctions might be run, including an examination of the question of auction design;

Section 4 examines some new issues, including whether auctions might reduce competitiveness exposure (through allowing border tax adjustments); reduce price volatility, and support long-term price signalling.

\section{The pros and cons of auctioning allowances}

\subsection{Economic efficiency, revenue recycling and the relationship to eco-taxation}

Raising revenue from environmental policy is not a new idea. The classical recommendation is to tax activities with 'external' (such as environmental) costs, to make firms factor these costs into their decisions (Pigou, 1920). A secondary benefit of such eco-taxation, in addition to internalising the environmental externality, is that the revenue raised can be 'recycled' to reduce other distortionary taxes on labour or capital in the economy. ${ }^{4}$

Despite the economic arguments for eco-taxation, implementation has been extremely patchy and highly contested. ${ }^{5}$ The divergence between theory and practice has gradually led to a much deeper appreciation of the crucial importance of the political economy of instrument choice. Policy decisions are strongly influenced, for understandable reasons, by the creation and allocation of economic rents. Environmental taxes have struggled to win political acceptance because they attempt to combine two difficult feats: transferring the rents created by environmental constraints

\footnotetext{
${ }^{4}$ This corresponds to a very simplistic statement of the 'double dividend' hypothesis. Various definitions are used in the literature, sometimes inconsistently, including 'weak', 'intermediate' and 'strong' forms. This terminology is avoided here. Tax-interaction effects are discussed below.

${ }^{5}$ See, e.g. Helm (2005).
} 
to the public purse, and providing incentives to change behaviour at the margins. ${ }^{6}$ Attempting either feat alone, particularly the former, can generate strong opposition from powerful interest groups.

In addition to the political economy challenges, policies internalising the carbon price (including taxes, and trading schemes whether the permits are grandfathered or auctioned) may have unwanted interactions with other taxes. ${ }^{7}$ For instance, imposing a carbon price by a tax or trading scheme raises the price of energy and derived products, which (other things being equal) reduces real wages and labour supply. Some considerations and studies suggest this indirect 'tax-interaction' effect more than offsets the efficiency gains from revenue recycling, though the net effects remain disputed and context-dependent. ${ }^{8}$

But any policy that internalises the carbon price without raising revenue (such as emissions trading with free allocation) suffers these tax-interaction effects without the benefit of the revenue-recycling effect (discussed above). ${ }^{9}$ Because auctioning allowances does benefit from the revenue-recycling effect, is almost certainly more efficient than free allocation, within the constraints of competitiveness effects. Thus, in practice, given that there is an emissions trading system in place, it is unambiguous that auctioning has the potential to improve the macroeconomic efficiency of the system.

\footnotetext{
6 A 2006 Special Issue of the Energy Policy Journal (34:8) analyses the European experience with ecotaxation and points to deeper underlying issues about the degree of public understanding and trust in political processes. A Swedish survey also underlines that attitudes to carbon taxation are directly related to the degree of trust in politicians, more even than individual's own exposure to the taxes (Hammar and Jagers, 2006).

${ }^{7}$ See Bovenberg and de Mooij (1994), the critique by Fullerton (1997) and the reply by Bovenberg and de Mooij (1997), as well as Bovenberg and van der Ploeg (1994), Goulder (1995), Parry (1995) and Bovenberg and Goulder (1996).

${ }^{8}$ Parry (2003) finds that the tax-interaction effect dominates the revenue-recycling effect. This would be expected from the optimal tax theory result that broad taxes produce lower efficiency losses than narrow taxes (e.g. Diamond and Mirrlees, 1971). In practice, the net impact depends on a wide variety of assumptions about the current tax base, whether the economy is modelled as a fully-deployed equilibrium, etc (IPCC, 2001, Chapters 7 and 8).

9 See Goulder, Parry and Burtraw (1997), Parry, Williams and Goulder (1999), Goulder, Williams and Burtraw (1999), and Fullerton and Metcalf (2001). The tax interaction effect could provide an argument for a carbon price that is below the Pigouvian level. It is not an argument for not raising revenue.
} 
Of course, efficiency considerations are merely the beginning, and we now examine five other considerations relevant to auctions, namely: the distribution of the economic rents created by $\mathrm{CO}_{2}$ limits in the economy; competitiveness effects of auctioning compared to grandfathering; dynamic incentives, and transaction costs.

\subsection{Rent distribution and equity considerations}

Limiting $\mathrm{CO}_{2}$ emissions puts a price on carbon and thereby increases production costs. Firms will pass a proportion of this marginal cost increase through to consumers. The proportion passed through depends upon the market structure. ${ }^{10}$ When allowances are freely allocated to firms, some participating sectors will inevitably make profits. ${ }^{11}$

It is now beyond doubt that the electricity sector generally profits from free allowances under the EU ETS, unless it is subject to direct price regulation or regulatory threat in concentrated markets, because generators pass costs on to electricity consumers, including non-ETS sectors and domestic consumers. Whether other participating sectors may similarly profit depends upon two main factors: whether they receive enough allowances to cover any increase in their cost base; and the constraints on cost passthrough placed by international competition. ${ }^{12}$ In practice, of course, these factors vary considerably between sectors, and indeed, companies and facilities within sectors. Nonparticipating sectors with high electricity consumption (such as aluminium) will face substantially higher costs due to higher electricity prices, and yet are not compensated through the receipt of free allowances.

Not only does the ETS have significant distributional consequences between the various sectors (participating or not), it is also clear that most of the economic rents from the current arrangements ultimately accrue to shareholders of the profiting firms, who tend to be wealthier than the general population. As such, in aggregate the current arrangements transfer resources from poor to rich. ${ }^{13}$

\footnotetext{
${ }^{10}$ See the companion papers in this Issue by Smale et al. and Demailly et al., also Hepburn, Quah and Ritz (2006).

${ }^{11}$ Indeed, Smale et al. (this Issue) suggest that most participating sectors will profit.

12 There is some indication that non-power sectors with significant emission levels are also able to pass through a proportion of the marginal cost increase. See, for instance, de Leyva and Lekander (2003).

${ }^{13}$ Parry (2003) points out that in the U.S. the top income quintile owns $60 \%$ of all shares with the bottom owning less than $2 \%$. A survey commissioned by Wall Street Europe concludes that in the US $60 \%$ of
} 
One of the widest economic misconceptions about auctioning is that it would simply add costs which would be passed through to 'downstream' companies and consumers. ${ }^{14}$ Yet if firms maximise profits, then even with free allocation they pass on the opportunity costs of allowances to downstream prices. Changing from free allocation to auctioning will have little impact on product prices. ${ }^{15}$ However, because auctioning raises revenue that may be reallocated, it has, prima facie, the potential to correct distributional impacts.

If auction revenues are employed to reduce general taxes, the distributional impacts will depend upon the nature of these other tax changes: for example, reduction in income tax would tend to shift revenue from electricity consumer to taxpayer, and if focused on the base rate might be somewhat progressive. Alternatively, direct dedication of the auction revenue to domestic consumers would give consumers an income stream that increases with higher $\mathrm{CO}_{2}$ prices, thereby compensating for product (especially electricity) price increases. This might also increase public interest in and support for the ETS. Few generalisations are meaningful at this level, however, since each country will have different political preferences and considerations in the context of wider tax and consumer debates.

If revenues are earmarked within the business sector, distributional impacts will similarly hinge upon how these revenues are targeted. One example of national earmarking is the UK Carbon Trust, which receives revenues from the UK Climate Change Levy that is then used to support investment by UK companies in improving energy efficiency, and in the process of commercialising new and emerging low carbon technologies. The aim is both to reduce energy costs for British companies and enhance their longer-term competitiveness by accelerating the use of advanced technology. In general, the use of $\mathrm{CO}_{2}$ auction revenues to support $\mathrm{R} \& \mathrm{D}$, demonstration projects,

households have equity ownership, while in Europe this number is only $18 \%$. Likewise, while in the US 50\% of population has more than Euro 50k private ownership excluding property, this compares to only $15 \%$ in Europe. (GfK Custom Research Worldwide, Sep/Oct 2004, 14383 people in 18 countries)

${ }^{14}$ Cramton and Kerr (2002) note that in the U.S. cellular communications licence example, prices happened to fell when the scheme shifted from free allocation to auctions because of an increase in competition.

15 Some cost differential might be expected by the logic in section 2.5 below on the perverse dynamic incentives created by repeated free allocations. The fact that the assumption of profit maximisation does not fully capture reality is discussed in section 4.1 . 
regional development bodies and possibly also supporting infrastructure is likely to be viable under state aid rules.

However, the use of auction revenues to mitigate the impact on downstream sectors (such as aluminium) on a larger scale is likely to be somewhat limited by state aid considerations (see below). Nevertheless, by introducing an additional degree of freedom, auctioning some fraction of allowances creates the potential for a more equitable distribution of the economic rents associated with emissions trading.

\subsection{Competitiveness effects}

Just as it is widely (but usually wrongly) assumed that auctions lead to increased costs on downstream consumers, it is also widely assumed that free allocation helps to reduce potential adverse impacts of the EU ETS on the competitiveness of European industry relative to countries without $\mathrm{CO}_{2}$ controls.

However, many participating sectors, such as the electricity sector, are not directly exposed to foreign competition, so competitiveness concerns are not directly relevant. Exceptions may apply to closure and investment decisions, which are affected by the allocation of free allowances - as illustrated at the example of the power sector in Neuhoff et al. (this Issue). Furthermore, although downstream industries are affected by increased electricity prices, recall that the electricity price increases they face should not differ much under grandfathering or auctioning.

Competitiveness concerns arise mainly in the sectors which (i) face significant cost increases, and (ii) are most exposed to competition from outside of the ETS. This includes industries like cement, steel, non-ferrous metals and some chemical products. Although the shift from grandfathering to auctioning does not normally have much impact on costs at the margin, ${ }^{16}$ it does affect is the gross revenues of companies. Free allocation is essentially a one-off subsidy that helps companies maintain a good balance sheet in the face of higher operating costs. Auctioning reduces the scale of that subsidy. Alternatively, for companies which are not focused on near-term profit maximisation,

\footnotetext{
${ }^{16}$ As already noted, an exception may apply when the allocation method has perverse dynamic effects, as discussed in section 2.5 .
} 
free allocation provides a subsidy to fund the protection of market share by underpricing (e.g. limit pricing, see Smale at al., this Issue), and auctioning reduces that capacity. As such, the general conclusion is that free allocation can act as a temporary subsidy to support firm balance sheets, but the choice between this and auctioning does not fundamentally change competitiveness in the longer term.

\subsection{Legal considerations}

As grandfathering and auctioning are mechanisms which allocate valuable assets, legal considerations are relevant. State aid considerations may place limits on the scope of free allocation. On the other hand, legal arguments might be put to support the view that firms have the 'right to emit' which cannot be taken from them, or that auctioning would adversely affect decisions that were made in reliance upon previous regulatory structures remaining in place.

The view that firms have a right to compensation for the establishment of, or changes to, the EU ETS, can be dispensed with rather quickly. It is clear that legislative bodies have the authority to change regulatory frameworks, particularly when regulated activities are harming others; indeed, there was never a 'right to emit' but only the freedom to do so until regulation provided otherwise. The argument that investors should be compensated for decisions made prior to the EU ETS (such as building a coal power station in 2000) relying upon the assumption that no new regulation would enter into force is only marginally more persuasive - it is well established that if government has a good public interest reason, it can restrain the use of an asset and there is no legal obligation to compensate as long as only the use is constrained but no expropriation performed.

Even if firms have no right to compensation, governments may wish to compensate adversely affected industry to enhance the credibility of their claims of investment certainty, and to continue to attract private sector investment. However, absent a specific justification, payments to industry may, prima facie, constitute state aid. A justification might be provided by analogy to the 'stranded cost regime' formulated and applied by the Commission under the 1996 electricity directive, which allowed for such 
compensation in the electricity sector. Similar arguments might be applied to other sectors.

If governments want to compensate investors for adjustment to regulation/legislation, this would motivate some free allocation of allowances during a transitory period to compensate investors that made investment decisions before there was reasonable expectation of carbon controls. Different views exist about when this was. Most of those involved in the international process would argue it to have been $1990^{17}$ or a couple of years thereafter. ${ }^{18}$ Later relevant landmarks include the adoption of the Kyoto Protocol in 1997, the EU's Green Paper on emissions trading in 2000, and the EU's ratification of the Protocol and adoption of the ETS Directive in 2002. Whatever year is considered applicable, however, as time passes fewer and fewer investments will be able to make the claim that costs were sunk before a reasonable expectation of carbon controls.

Far from having a right to compensation, the balance of legal arguments seem heavily (and increasingly) weighted to the view that any such compensation is prohibited under state aid rules. Indeed, European competition law may create pressures to reduce the free allocations to industrial emitters so that they are proportionate with the (otherwise) forgone profits from to the introduction of ETS (Johnston, this Issue).

Finally, requiring firms to pay for the right to pollute is consistent with the polluter pays principle, which starts from the premise that the right to a clean environment is owned by the public: from this basis, if firms wish to pollute the environment, they must purchase the right to do so from the public, rather than being given it for free.

The clear conclusion is, therefore, that legal principles are a very shaky basis from which to argue against auctioning. On the contrary, legal considerations suggest that auctions may be favoured over free allocations.

\footnotetext{
${ }^{17}$ The publication of the IPCC's First Assessment Report and the UN General Assembly Decision to launch negotiations on tackling climate change.

${ }^{18}$ The UN Framework Convention on Climate Change, which agreed on the nature of the problem and the need for action led by industrialised countries, was signed at the Rio Earth Summit in June 1992 and ratified by the US Senate later the same year, and entered into force a year later. It was also in the period 1990-1992 that the EU developed proposals for a carbon tax, later made conditional on action by other countries.
} 


\subsection{Reducing distortions and perverse dynamic incentives}

An additional problem with free allocation is that it can lead to rather perverse dynamic incentives. For instance, if future allowances are allocated as a function of present emission levels, firms have an incentive to emit more now in order to extract a larger allocation in the future. ${ }^{19}$ Similarly, if free allocation to existing installations is relatively generous, while allocations to new installations are more restrictive (as it is in many Member States) incentives are created for plant lifetime-extension rather than plant modernization or replacement. This is analogous to the 'ratchet effect' in economic theory, ${ }^{20}$ and clearly reduces the efficiency of the trading scheme. No such perverse incentives arise when allowances are auctioned and the emissions market is relatively competitive.

This phenomenon arises in two other papers in this Issue. In the electricity sector, Neuhoff et al. (this Issue) illustrate that the sheer value of free allocations in a sequentially negotiated trading systems makes it hard to avoid some distortionary effects. Damien et al. (this Issue) also confirm that if allowances are allocated as a function of production whether contemporaneously (as in 'output-based' allocation) or in the future (as with updating), output choices are correspondingly distorted. Auctioning would, obviously, reduce or eliminate these effects.

\subsection{Transaction costs of allocation processes}

The final 'traditional' area of dispute concerns administrative costs. The Phase I National Allocation Plans involved negotiation over allowances with a total asset value of almost $€ 50 \mathrm{bn} / \mathrm{yr}$ (assuming an average price of $€ 20 / \mathrm{t} \mathrm{CO}$ ). Political decisions on how to allocate these assets between sectors and individual installations naturally creates intensive lobby activity by all participants to obtain the maximum possible share of the rents. ${ }^{21}$ The time and energy devoted by companies, governments and indeed consultancy and

\footnotetext{
19 Additionally, if the rules provide for higher allocations to dirtier new entrants, then entrants have an incentive to construct more carbon intensive facilities than is economically efficient.

${ }^{20}$ The basic ratchet effect is described by Freixas, Guesnerie and Tirole (1985).

${ }^{21}$ The need for lobbying may exacerbate the dynamic incentive effects discussed in Section 2.5 if firms make inefficient investment decisions to improve their bargaining position for free allowances.
} 
research sectors to this enormous rent allocation process represents huge transactional costs. $^{22}$

Estimates of transactional costs must account for the fact that the allocation process imposes significant risks upon both firms and government. Many firms fear being 'caught short', and these fears may be amplified by their lack of experience and confidence in trading on the secondary market and concerns about the future availability of permits. The government (and the public at large) bear the risk that the allocation process will end up being unfair on some sectors, and overly generous to others. The government's response to this risk is to devote considerable resources to the process of 'allocation assessment'. Furthermore, transactional costs involved in free allocation are likely to increase in the future, as more complex allocation schemes (e.g. benchmarking) are employed to reduce other unwanted consequences.

In principle, auctioning more of the allowances reduces the volume of free assets open to lobbying, and therefore reduces the 'rent scrap' of these allocation negotiations. It would also help both firms and government manage their real and perceived risks - firms are less likely to be 'caught short' when they can buy permits at the next auction, and governments could redeploy their resources now spent on 'allocation assessment'. Of course, auctioning also involves administrative and other transaction costs. Thus, whether auctioning increases the overall implementation efficiency of the EU ETS may depend upon the design of the auctions, which we consider shortly.

\subsection{Summary of the traditional arguments}

Table 1 presents a summary of the arguments considered in this section. In addition to the reasons favouring some auctioning compared to $100 \%$ free allocation, it is notable that some auctioning might be preferred to simply cutting back free allocations by the same amount. If the market is liquid and - as considered below - auctions are open to all bidders, the choice between buying at auction and buying on the secondary market may make little difference to individual companies. However, at the economy-wide

\footnotetext{
${ }^{22}$ The relative paucity of published academic work on this huge scheme is evidence of this process - most academics and think tanks are caught in extensive consulting exercises for either governments or industrial participants on the rent allocation, rather than devoting their attention to forward looking studies on how to create innovation, least cost abatement and appropriate institutional changes.
} 
level, auctions release allowances into the market and thus do not raise the carbon price as much as cutbacks of the same quantity. They also have more desirable characteristics in terms of macroeconomic efficiency, distribution and lessening of perverse dynamic incentives, as discussed. We now turn to examine how allowance auctions might be designed.

Table 1: Summary of issues

\begin{tabular}{|l|l|}
\hline Issue & Favours \\
\hline Static efficiency & Auctions \\
\hline Distribution of rents & Auctions in theory, free allocation in practice \\
\hline Competitiveness & Depends upon use of auction revenues \\
\hline Legal considerations & Auctions \\
\hline Dynamic incentives & Auctions \\
\hline Transactions costs & Uncertain, favours auctions in medium term \\
\hline
\end{tabular}

\section{How to auction EU ETS allowances}

The allocation of EU ETS allowances has several features in common with the sale of government securities such as T-Bills and Gilts, provided Member States do not impose strong restrictions on participation. ${ }^{23}$ In both cases there is a large number of potential bidders and a large number of identical goods which can subsequently be traded on a secondary market. Member States therefore have an opportunity to create a very competitive and efficient auction environment, as in the case of securities. Bearing in mind these similarities, we discuss some basic issues for the design of EU ETS auctions.

\subsection{Multi-unit auction design}

There are many possible formats for auctions of EU ETS allowances which can be divided into two broad types. These are ascending-bid auctions, in which bidders have the opportunity to raise their bids during the auction, and sealed-bid auctions in which bidders submit only their final offers. The preferred choice of format depends on the circumstances. For example, ascending-bid auctions may be easier to understand for inexperienced bidders and have been recommended for auctions of UK greenhouse gas

\footnotetext{
${ }^{23}$ Eligibility and participation issues are considered in section 3.2 below.
} 
emissions reductions in 2002 (Klemperer, 2004 p.135) and the New Entrants Reserve (NER) in Phase I of the EU ETS in the UK (DTI, 2005). ${ }^{24}$ However, in the case of EU ETS allowances, as long as Member States do not unnecessarily restrict competition in auctions (e.g. by allowing only one sector to participate in any given auction), there are many potential bidders and sealed-bid auctions should perform well.

In a sealed-bid auction, participating bidders submit confidential bids in the form of demand schedules, which specify how many permits a bidder would be willing to buy at any given price. These bids are added together to form an aggregate demand curve and a market clearing price is determined as the point at which aggregate demand equals supply. Winning bids are identified as those above the clearing price. Figure 1(a) provides an illustration of a sealed-bid auction, where Pc denotes the market clearing price. In section 4.2 below, we discuss the idea of Member States agreeing a reserve price for auctioned allowances. Figure 1(b) shows an example where this reserve price, PMIN, binds. In the case shown, PMIN is higher than the clearing price, so not all the allowances are sold at auction.

\footnotetext{
24 The 2002 auction of emissions reductions was a reverse auction in which bidders competed to sell reductions to the government. Concerns about encouraging entry led to the use of a descending-bid auction format (the mirror image of ascending bids in a standard auction). The fact that this was the first ever auction for greenhouse gas reductions and the relatively small scale of the market meant that small bidders could have been deterred by the costs of having to formulate a strategy in a sealed-bid auction. (The small scale of the auction meant that having a non-competitive bid facility of the kind that would mitigate these concerns would be impractical.) The government was keen to promote entry both to increase competition in the auction itself and to ensure a liquid secondary market (Klemperer et al., forthcoming).
} 
Figure 1: Market clearing price

(a) without a minimum price

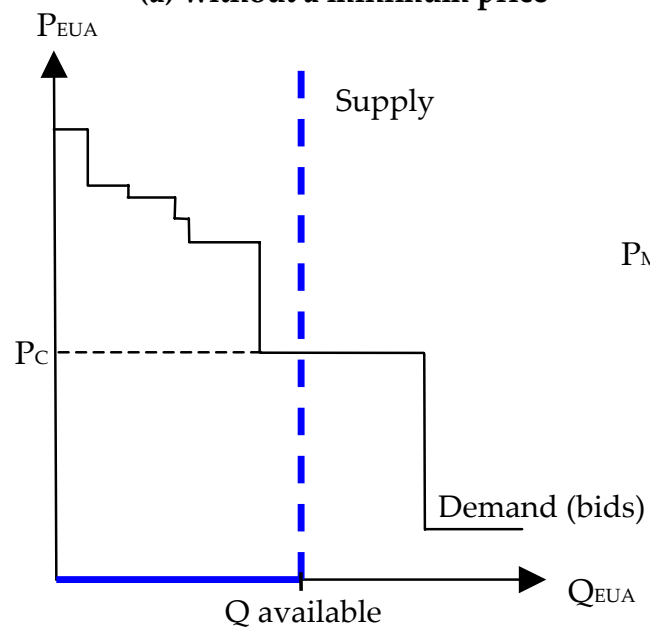

(b) with a minimum price

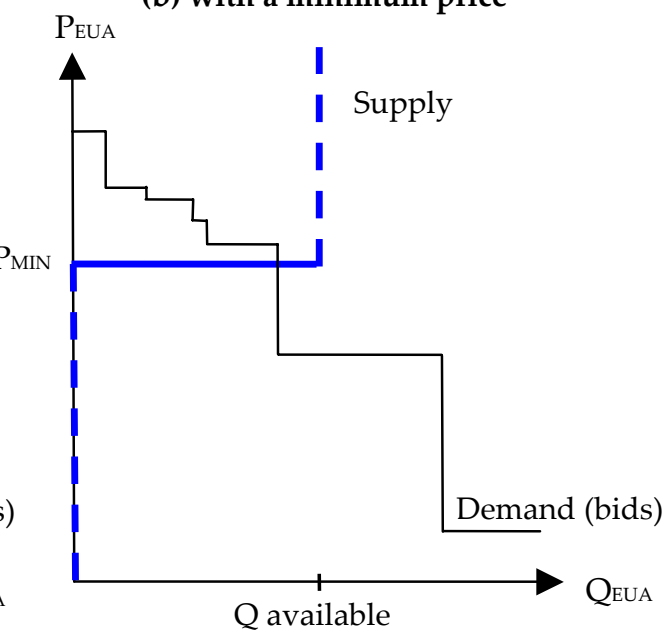

Two variants of the sealed bid auction are the discriminatory and uniform-price formats commonly used to issue government securities. The two formats differ in the payments that winning bidders must make. In a uniform-price auction, every winning bidder pays the market clearing price. In a discriminatory auction, every winning bidder pays its own bid for the units it wins. For example a bidder who bids for 20 permits at $€ 30$ each and a further 10 units at $€ 20$ each pays a total of $€ 800$ if all the bids are above the market clearing price. ${ }^{25}$

Because both formats are now well established, Member States and potential bidders would be - or could easily become - familiar with the rules of either auction. Using these familiar formats would also address concerns about auctions being untested or over-complicated. Both discriminatory and uniform-price formats would be feasible and low-cost for Member States. ${ }^{26}$

\footnotetext{
${ }^{25}$ An alternative type of sealed-bid auction is the Vickrey auction, where a winning bidder's payments equal the bids of the losers who would have won in the absence of his participation. The winner thus pays the opportunity cost of his bid. Vickrey auctions are of great interest to academic auction theorists and have been shown to have desirable theoretical properties (Ausubel and Cramton, 1998). However Vickrey auctions are much harder for participants and the public to understand, and as long as bidders have very little market power uniform-price auctions produce similar results.

${ }^{26}$ This is not to say that alternatives should not be considered, or that either option is necessarily the preferred auction format for every Member State. However the low costs of such formats (e.g. compared with ascending bids) and the fact that Member States can draw on the experiences of securities markets suggest that discriminatory and uniform-price auctions should be thoroughly examined.
} 
There are two important considerations relevant to the choice between uniform and discriminatory formats. First, it is often argued that it is simpler for bidders to formulate bidding strategies in a uniform price auction, promoting participation and competition. In a discriminatory auction, small or inexperienced bidders may find it difficult to anticipate the market clearing price and may be deterred from bidding for fear of making costly mistakes. ${ }^{27}$ This might arise if secondary and futures markets are illiquid and there is a great deal of uncertainty over prices. ${ }^{28}$ In the case of EU ETS allowances, one would expect greater uncertainty towards the beginning of a trading period (e.g. in the year 2008 for the 2008-12 period) when fewer allowance trades will have occurred.

If low participation by smaller bidders is a concern, non-competitive bids could be permitted. A bidder who submits a non-competitive bid is guaranteed to win the desired units in the auction. In a uniform-price auction, the price is simply the market clearing price, while under discriminatory pricing the non-competitive price is an average of the conventional winning bids. Bidders can therefore limit risk by submitting non-competitive bids, particularly in discriminatory auctions. ${ }^{29}$

Second, the revenue raised may differ between pricing formats. Without reflection, one might expect uniform-price auctions to raise less revenue than discriminatory auctions, where bidders pay their bid. However, this ignores the fact that bidders will adopt different bidding strategies under different auction formats. In a discriminatory auction, bidders have a strong incentive to shade (i.e. lower) all of their bids in order to avoid paying much more than they need to for each unit. In a uniform-price auction, bidders will only shade their bids if they think that this may influence the market clearing price.

\footnotetext{
${ }^{27}$ One possible problem is the "winner's curse". The value of winning a tradable allowance is similar for bidders because they will all face the same resale price on the secondary market. In this kind of "common value" auction, the bidders estimate what this price will be and bid accordingly. However the most likely to win is also the most likely to have overestimated the price, and bidders need to shade their bids to account for this.

28 In the United Kingdom, index-linked securities (gilts) are sold in a uniform-price auction, while conventional gilts are sold using discriminatory pricing. The Debt Management Office explicitly attributes this decision to the greater uncertainty surrounding prices of index-linked gilts and the illiquidity of secondary markets.

${ }^{29}$ If non-competitive bids are permitted in securities auctions they typically comprise a small proportion (about $10-20 \%$ ) of the issue.
} 
As such, it is not clear ex ante which auction will produce higher revenues or more efficient allocations. ${ }^{30}$

Nevertheless, there is some evidence from securities auctions that uniform-pricing raises more revenue and produces less concentrated allocations (e.g. Archibald and Malvey, 1998), and it was partly on the basis of this evidence that the US Treasury switched to a uniform-price format in 1998. Furthermore, the UK Department of Trade and Industry expressed a preference for uniform over discriminatory pricing in Phase I NER auctions (DTI, 2005).

In summary, as long as entry by bidders is not artificially restricted, EU ETS auctions are likely to be very competitive and efficient. There are several possible auction formats, but the most likely candidates are the sealed-bid uniform-price and discriminatory auctions, used in sales of government securities. The limited evidence that we have slightly favours uniform-pricing, especially as bidders appear to find uniform-price auctions more straightforward. If participation is a concern, then non-competitive bids may be used.

\subsection{Eligibility and Participation}

The most important objectives of auction design are to promote competition and to encourage entry. Consequently auctions for EU ETS allowances should ensure the widest possible participation by bidders from all sectors. Artificially restricting participation to national buyers or specific sectors is likely to impair revenues and the efficient allocation of allowances.

Nevertheless, only one of the four governments that auctioned in Phase I opened the auction to all EU bidders. Given that allowances are readily tradable, national or sectoral bidders will only benefit from restrictions on participation if auction prices are significantly lower than those in the secondary market. Despite the arbitrage possibility, prices at auction may be lower than on the secondary market if poor auction design

\footnotetext{
30 There is also the possibility of 'demand reduction' in uniform-price auctions (Ausubel and Cramton, 2002).
} 
facilitates non-competitive or collusive behaviour by bidders. The net result would be a reduction in revenue and an implicit subsidy for bidders. ${ }^{31}$

Increasing the number of eligible bidders is desirable because it is likely to lead to greater competition and higher auction revenues. However, even if they are eligible, small bidders are unlikely to participate directly in auctions because of the transaction costs involved in formulating and submitting bids. Moreover the institutions responsible for conducting the auctions face costs in dealing with each bidder (e.g. in ensuring compliance with capital requirements or securities regulations).

One option is to allow current dealers on the ETS secondary market to become "primary dealers" who can bid on their own accounts or on behalf of clients. Because these dealers would participate more regularly than individual buyers some transaction costs could be avoided. Small buyers might even be encouraged to participate via a dealer when they would not be willing or able to do so directly.

In order to prevent either primary dealers or their clients from manipulating the auction price, limits could be set on the size of any individual bidder's share of the allowances allocated in an auction. Manipulations of the secondary market (such as 'short squeezes') will probably not be a major consideration as the proportion of allowances sold at auction will be relatively small. ${ }^{32}$

\subsection{Allocation of free allowances}

Obviously, auctioning allowances in Phase II reduces the allowances that are available for free allocation. Governments must determine how the remaining free allocations are distributed between sectors. An obvious and simple approach is simply to reduce the allocation to all sectors by $10 \%$ (or the proportion chosen for auction). Nevertheless, given the differential pass-through of costs between sectors, discussed in section 2.2 above, it may be considered politically appropriate to compensate for undesirable

\footnotetext{
${ }^{31}$ This is then equivalent to partial grandfathering, and the various arguments discussed in Section 2 above are applicable. If such subsidies are justified in some manner, there would be better ways of delivering them than by distorting the auction design.

${ }^{32}$ US treasury auctions restrict bidders to $35 \%$ of supply in any auction but these rules have occasionally been circumvented. In 1991 Salomon Brothers admitted to submitting fraudulent bids in the names of their clients in order to squeeze short sellers in the "when-issued" market.
} 
distributional consequences by adjusting the allocation between sectors. For instance, sectors with higher rates of cost pass-through might receive a smaller share of free allocation, while others would receive a more generous allocation.

\subsection{Auction periodicity}

The principles

How often should auctions be performed? At one extreme, the entire allocation could be sold at the beginning of the five-year period. Large infrequent auctions would minimize administrative and transaction costs and might also promote competitive bidding between bidders for whom this is the only chance to buy allowances at auction. However, for a number of reasons we believe that more regular auctions are advisable.

Smaller and more frequent auctions are likely to encourage participation by smaller bidders. For example, firms who wish to purchase at auction rather than on the secondary market may not have a large enough line of credit to purchase five years worth of permits in advance. This is a substantial asset to hold on the balance sheet and one-off auctions might deter small bidders without "deep pockets". These bidders would still trade on the secondary market but the auctions themselves would be less competitive.

By providing a steady injection of liquidity more frequent auctions would limit the impact of any individual auction on market prices. Periodic auctions might also enhance price stability and the management of uncertainty, as discussed below in Section 4. Although market interactions are unlikely to be problematic for Phase II, where only $10 \%$ of allowances can be auctioned, the impact on the market is likely to become more important if and as a greater proportion of allowances are auctioned over time. ${ }^{33}$ Furthermore smaller auctions reduce or eliminate any residual (and probably unjustified) concern that participants with market power would buy large fractions of the allowances and subsequently extract oligopoly rents on the secondary market. Multiple auctions would allow other players to adjust their bids in later auctions in response to any initial strategic purchasing by large players.

\footnotetext{
${ }^{33}$ Auctioning permits all at once would increase liquidity in the secondary market. However since only $10 \%$ of allowances will be sold at auction this is unlikely to be a major concern.
} 
Auction frequency with 25 countries.

Finally, periodicity also depends upon whether Member States coordinate their auctions. If Member States run their auctions independently, then staggering their timing would ensure a gradual release of liquidity. For instance, if all 25 Member States run quarterly auctions, there would be two allowance auctions every week, which seems too frequent. Even annual national auctions could result in an auction somewhere in Europe every two weeks. At the opposite extreme, Member States could collaborate and coordinate the timing of their auctions, considered briefly below.

The ideal trade-off between ensuring a competitive auction with low transactions costs and providing steady liquidity is difficult to judge before we have gained more experience with allowance auctions. If auctions were to be based on experience with electricity markets, then a frequent uniform price auction (e.g. weekly), would allow small participants to directly acquire the allowances they need to cover their emissions in the auction. ${ }^{34}$ High frequency would ensure that bidders pay a price close to the price on the secondary market at the time of emission, thus limiting risk exposure. In electricity markets this approach has been successfully implemented with low transaction costs (various pool type market designs).

If, on the other hand, EU ETS auctions were to be more guided by the experience of Treasury bill auctions, then less frequent auctions (e.g. 1-3 times a year) would be envisaged. A simple uniform price format might be employed, but less frequent auctions would also allow the use of a wider range of auction formats. Of course, a more complex auction format, requiring more careful preparation of the bid, would increase the costs for small players to directly participate in the auction. Very small players are therefore likely to obtain their allowances from intermediaries, who would provide risk hedging and other services, arguably at a cost reflected in lower auction revenue. This approach also has the benefit of supporting liquidity in $\mathrm{CO}_{2}$ spot markets.

\footnotetext{
${ }^{34}$ A discriminatory price auction with non-competitive bids could also be used.
} 
Finally, note that Member States could consider auctioning in advance; auctions for 2008-12 allowances, for example, could and probably should be held before 2008 to help the market form price expectations.

\subsection{Auction competition and coordination}

In principle there is no reason why Member States should not hold auctions entirely independently of each other. The question of how actions in one country might affect others would then need to be considered; in effect, governments themselves might become active "market players", judging the timing and volume of auctions in relation to market projections, including expectations about the auction decisions of other Member States - a kind of "auction competition". It is not clear how desirable it would be for the legal authorities responsible for forming the market to then become active players in it, and whether this might lead to conflicts of interest. How numerous auctions might interact with the auction method is another issue to be considered especially if some of the auctions are very small, enabling large players to influence the outcome.

For these and other reasons, Member States might consider "pooling" auctions under the same rules. In particular Member States with fewer allowances to sell might decide to hold joint auctions and to divide the revenue according to their share of supply. Coordinating the timing of auctions might also aid price stabilisation.

The ultimate manifestation of this would be for all countries that hold auctions to pool together, in EU-level auctions. It is unlikely that Member States would give up revenues, but that is a separate issue; there would be nothing to prevent central EU institutions managing the auctions and returning revenues to Member States. De-linking decisions on auctions in this way from the revenues generated would avoid any potential conflict of interest. And to have some element of EU-level auctions may be inescapable for some of the more "active uses" of auctioning, to which we now turn. 


\section{Active auctioning: hedging, pricing and border adjustments}

Section 2 above set out the main debates around auctioning, concluding that these offer strong arguments for a degree of auctioning, probably increasing over time. Section 3 indicated that there are no significant operational problems in conducting such auctions. In our view, however, these are not necessarily the only interesting and important benefits of auctioning. In addition to the distributional and incentive properties, there may be other important practical roles for auctions in the context of the EU ETS that have as yet been inadequately considered, and we now turn to examine these issues.

\subsection{Management attention}

Economic analysis tends to assume that firms maximise profits. This assumption drives the result, noted in section 2.2 above, that cost increases passed through to consumers should depend on the marginal cost increase - driven by the carbon price - not directly by the method of allocating allowances. In practice, although an assumption of narrow profit-maximisation is not egregiously wrong, it is an idealisation that obviously does not fully capture reality. The behaviour of people and firms embody considerable inertia and they often use heuristics and 'rules of thumb'. ${ }^{35}$ One relevant example from the energy sector emerges from the experience with financial transmission rights in the North East of the US. There it was found that the free allocation of transmission rights dampened the industry response to price signals. To increase responsiveness subsequently, all transmission rights were auctioned and revenues returned to initial owners of the rights.

If the allowances given to firms cover the bulk of their emissions, there is no risk exposure and few cash flows. In these conditions, the EU ETS may well be handled by environmental compliance departments, particularly in smaller companies, rather than moving up to affect investment, operational and strategic decision making. Indeed the design of the EU ETS and its focus on facilities itself reflects its origins in EU environmental regulation, with emphasis upon compliance. In these conditions, the current arrangement largely allows companies to carry on emitting as they would have

\footnotetext{
${ }^{35}$ As documented and analysed more fully in the growing literature on behavioural economics. For specific examples see Gigerenzer and Goldstein (1996) and Gigerenzer (2003). Of course, the use of heuristics per se is not necessarily inconsistent with profit maximisation.
} 
in the absence of the scheme. Worse, it may foster a psychology that firms must put their main emphasis upon lobbying for all the allowances they project to be needed, rather than on considering or implementing their real opportunities for abatement, particularly in sectors characterised by smaller firms or lower energy intensity.

Thus, the effectiveness of the trading system might be substantially improved by mechanisms which prompt an active response from management. Two options would appear to grab management attention, namely cutbacks in allocation and auctioning. Allowance cutbacks are also emerging as a way of addressing the profits accruing to the power sector. ${ }^{36}$ Given lobbying, market uncertainty and price volatility, as well as the macroeconomic dimensions considered in section 2 , auctioning might well be seen as the preferred method. Auctioning could help to get the desired response to the regulation, as the increased financial flows may shift management attention to include allowance costs when optimising production decisions. ${ }^{37}$

\subsection{Auctioning and price stability}

The economics literature sets out a strong case for fixing prices rather than capping quantities, in the context of a problem like climate change. ${ }^{38}$ The essential argument concerns the relative sensitivities of the benefits of mitigation, and the costs of control, when both are uncertain. If the marginal costs imposed by a given quantity constraint are very sensitive to the level of constraint (steep marginal cost schedule), but the marginal benefits of abatement relatively insensitive to the amount (a flat marginal damage schedule), ${ }^{39}$ then price-oriented controls are more efficient. ${ }^{40}$ Pizer (2002) finds

\footnotetext{
${ }^{36}$ Allowance cutbacks to power generators would reduce total allowances, increasing the allowance price. In contrast, auctioning would not have this effect. As such, downstream sectors should clearly prefer auctioning to an equivalent allocation cutback.

37 Auctions might also raise shareholder awareness of carbon costs, and alert them to the possibility of savings through abatement, resulting in greater pressure on managers to reduce emissions.

${ }^{38}$ Weitzman (1974) and Roberts and Spence (1976) provide the canonical theory. Pizer (2002) and Hoel and Karp, $(2001,2002)$ apply the theory to climate change, accounting for the fact that greenhouse gases are a "stock pollutant", not a "flow pollutant"..

${ }^{39}$ Note that assuming a flat marginal benefits curve does not imply that damages from climate change are small. It simply implies that damage from climate impacts do not change rapidly as a function of additional emissions. Assuming a flat marginal damage curve is probably accurate over a short period (e.g. 5 years), because climate damages are a function of the stock of greenhouse gases in the atmosphere, rather than the flow of emissions. This assumption is less appropriate over longer timeframes, and Hoel and Karp (2002) show that capping quantities becomes more attractive as the relevant policy time horizon is increased.
} 
that a price-oriented approach for near-term $\mathrm{CO}_{2}$ controls could yield many $\$$ billions in net social benefits. In contrast, an equivalent absolute emissions cap is far less attractive - if the cap is wrong, the economic costs may vastly exceed the environmental benefits. In practice, however, pure price instruments (such as a harmonised, long-term, credible global carbon tax) are still rarely applied to environmental problems.

The EU ETS experience has already revealed a more immediate and pragmatic problem. Since the market opened in January 2005, EU ETS prices have been very unstable. Difficulties in predicting future allowance prices are delaying investment decisions. By waiting, a company can gain more knowledge about future $\mathrm{CO}_{2}$ prices, and thereby make better decisions. Furthermore, in the presence of price uncertainty, risk aversion is also likely to reduce investment. ${ }^{41}$ The risk of low $\mathrm{CO}_{2}$ prices represent a significant hurdle for investment in low-carbon investments. Obviously, companies are prepared to bear risks, but they generally prefer to take risks in their core business, where this can create strategic opportunities. ${ }^{42}$

\footnotetext{
${ }^{40}$ See Hepburn (2006) for a simple presentation and review of the "prices vs. quantities" literature with an application to policy questions in health, transport, defence and the environment.

${ }^{41}$ These are classic results of real option theory. See Baldursson and von der Fehr (2004) for a more sophisticated discussion of this issue.

${ }^{42}$ Furthermore, asymmetries in risk hedging and allocation have an impact. Utilities in the power sector (with a more conservative risk profile and relatively restrictive allocations) have needed to buy from other sectors, which were under no pressure to sell surplus allowances. This sellers' market arguably inflated prices. Auctions on a regular basis (e.g. biannually) would improve directly and indirectly the liquidity of the market by reducing this type of problem.
} 
Figure 2. Uncertainty on emissions from installations covered by the EU ETS

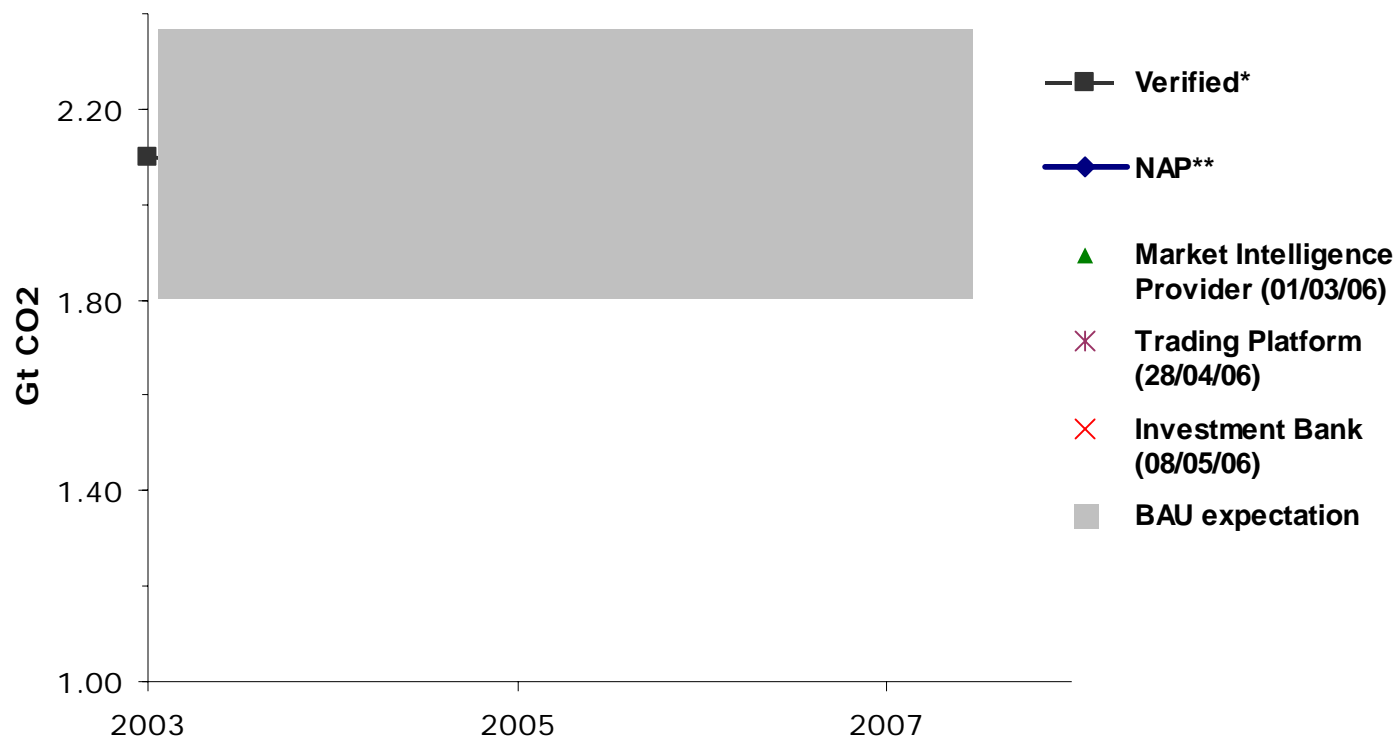

The sheer scale of price risk faced by EU ETS participants is illustrated by figure 2. It shows the range of predictions of $\mathrm{CO}_{2}$ emissions for the first EU ETS phase, based on preliminary data from the European Commission for verified emissions for 21 of the 25 countries covered by the EU ETS. ${ }^{43}$ This data suggests that the scheme was $86 \mathrm{Mt}$ long of allowances during 2005. The range of predictions expressed by different market players before the publication of the official EC results, as shown by figure 2, illustrates the uncertainty inherent in predicting emissions.

Clearly, policies which can provide a greater degree of price stability in the EU ETS would be valuable.

An extreme solution to the problem of price uncertainty would be to impose a price ceiling and a price floor on the market. ${ }^{44}$ A price ceiling would be established if an appropriate government institution agreed to provide an unlimited supply of permits to the EU ETS secondary market at a fixed price. ${ }^{45}$ Such an arrangement would be difficult

\footnotetext{
${ }^{43}$ It is assumed that Poland, the main unknown, has an $18 \%$ excess allocation, similar to Hungary and Czech Republic.

${ }^{44}$ In the limit, if the ceiling and the floor are equal then obviously the allowance price would be fixed, and what was 'quantity instrument' would now effectively become a 'price instrument'.

${ }^{45}$ See, eg, Pizer (1997, 2002), Aldy, Orszag and Stiglitz (2001), McKibben and Wilcoxen (2002), and Jacoby and Ellerman (2004).
} 
to align with the commitment of European Member States to their cap under Kyoto. ${ }^{46}$ In any event, with only $10 \%$ of the allowances available to auction in Phase II, there is no practical way in which auctions could set an 'unbreakable' price ceiling.

A price floor in the EU ETS could be established if a government institution agreed to purchase an unlimited number of permits at a fixed price. If sellers are guaranteed this floor price by selling to the government, the market price will not fall below the floor. Treasuries, however, are typically reluctant to sign up to such financial liabilities.

Could auctions be employed to implement a price floor? Suppose all emissions allowances are auctioned and that inflows of allowances through the linking directive are restricted. Under these circumstances, governments could agree to only sell allowances above a reserve price of, for example, $€ 15 / t \mathrm{CO}_{2}$, thus establishing a price floor for EU ETS allowances.

Does the same argument translate to a situation where only $10 \%$ of allowances are auctioned? Here, although auctions cannot guarantee a particular price floor (because prices will depend upon broader market dynamics, discussed below), they may contribute to price stability. There are three cases to consider.

First, if supply of JI and CDM credits is limited or constrained (perhaps by additionality criteria), and if abatement is also limited or expensive, the participating sectors will want to purchase the $10 \%$ of auctioned allowances. In this case the reserve price in the auction, PMIN, translates to a price floor for ETS. Figure 3 illustrates this idea. In figure 3(a), without auctions, the EUA price $\mathrm{P}^{*}$ is determined by the point at which the demand curve crosses QKyoto. In figure 3(b), 10\% of the allowances are removed from circulation, and auctioned back at or above the reserve price, PMIN. A proportion of the auctioned allowances remains unsold, and the EU ETS price now equals PMIN.

\footnotetext{
${ }^{46}$ Furthermore, the EU directive prohibits ex-post adjustment of national allocation plans, hence national governments could not sell additional allowances after the submission of these plans.
} 
Figure 3: Auctions when JI/CDM supply is not important

(a) market without auctions

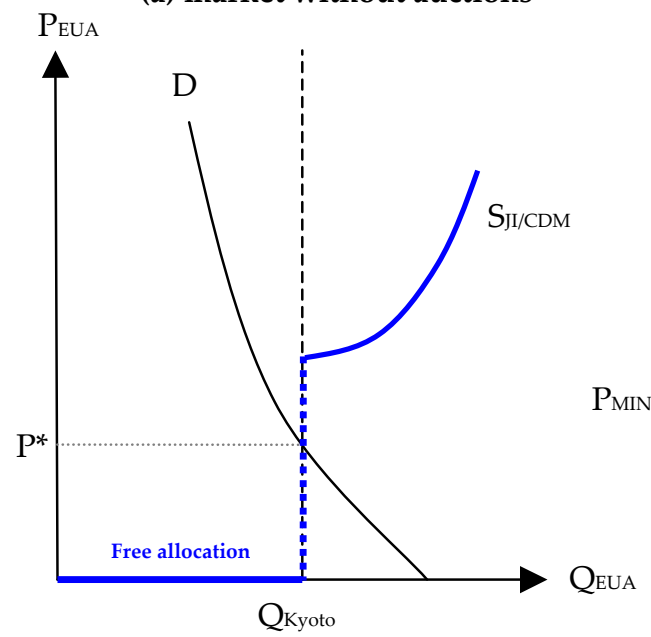

(b) market with auctions

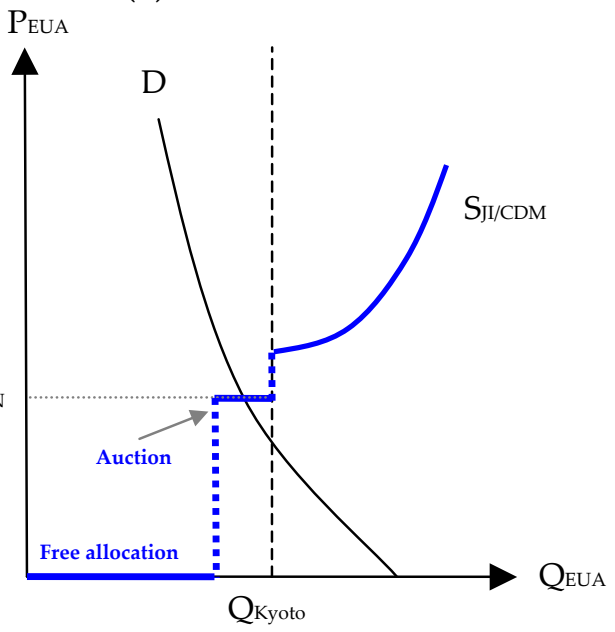

Second, if supply of JI and CDM credits increases significantly or large emission reductions are achieved in the ETS sector, then the allowance price could drop below the reserve price of the auction, as illustrated in Figure 4. The auction reserve price still increases the EU ETS price from $\mathrm{P}^{*}$ to $\mathrm{PA}^{*}$ (compare figures $4(\mathrm{a})$ and $4(\mathrm{~b})$ ), because the withdrawal of $10 \%$ of the allowances from the market ensures that the price is higher then it would have been otherwise.

Figure 4: Auctions when JI/CDM supply is important

(a) market without auctions

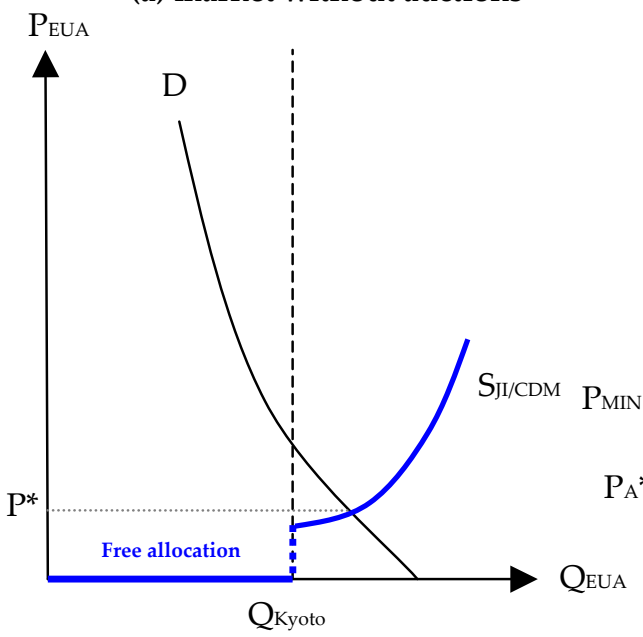

(b) market with auctions

Peua

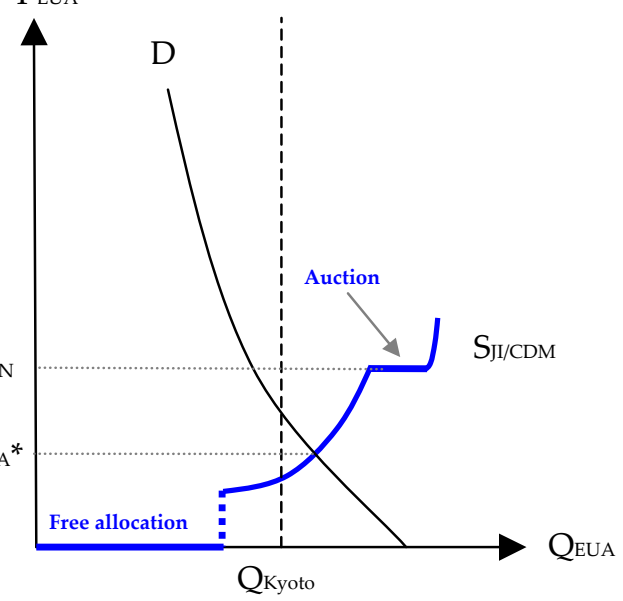


Third, with weak emission targets (or extremely cheap abatement) the allowance price might drop to zero, even if only $90 \%$ of the allowances are available. ${ }^{47}$ In this case the reserve price in the auction would have no impact on the allowance price. This theoretical possibility, however, seems highly unlikely.

Finally, note that the price floor in the auction, PMIN, will have no direct impact on ETS prices, if ETS prices already exceed PMIN. In this case all allowances will be auctioned. Nevertheless, there are indirect beneficial effects, including greater price stability ex ante, and hence increased investment in low carbon technologies.

It is unclear how difficult it would be to achieve coordination among Member States on a floor price. Ex ante it is a simple mechanism that improves the performance of the scheme, and should therefore be attractive to governments. Ex post some governments might be tempted to sell additional allowances, even at lower prices, if the floor price limits their sales volume. However, if governments continue to require private sector investment to achieve future emission reductions, then they are less likely to shutter the confidence of private sector investor with such activities.

So could auctions be used in practice to enhance price stability by supporting a 'price cushion' of the sort described in Figure 4? The design for capacity markets for electricity generation in various states of the North East of the US indicates that it may be possible. Applying this approach to the $\mathrm{CO}_{2}$ context suggests that governments could commit to a supply curve for additional $\mathrm{CO}_{2}$ allowances where, for example, the first lot of allowances from the auction budget might be sold at a minimum price of 20 Euro/t $\mathrm{CO}_{2}$, with increasing fraction of allowances sold at gradually increasing minimum prices. This allowance supply elasticity will complement the demand elasticity created by different abatement options and thus contributes to a reduction of $\mathrm{CO}_{2}$ allowance price volatility. The implementation of such a scheme in a multi-period, multi-country auction would, however, require careful consideration. Initial price stabilisation might reduce the incentive of market participants to hedge their decisions, potentially exposing them to

\footnotetext{
${ }^{47}$ This would be reflected in figure 3 by the demand curve shifting down to cut the axis in the free allocation area.
} 
even higher risk in the case that all available allowances are auctioned and prices become more peaky.

In sum, the foregoing analysis suggests that within the current EU directive, auctions might play a useful role in serving to support a cushion for prices, increasing investment security.

\subsection{The feasibility of border-tax adjustments}

It is difficult for energy intensive sectors to pass through the (opportunity) costs of $\mathrm{CO}_{2}$ allowances to product prices if these prices are set in international markets. Persistent price differences might, therefore, drive new investors to regions not covered by stringent emission trading schemes, as discussed more fully in Grubb et al., this Issue.

If the effective $\mathrm{CO}_{2}$ price differs between regions post 2012, investment in energyintensive industries is likely to gravitate towards regions with low or no $\mathrm{CO}_{2}$ prices. Clearly, stringent $\mathrm{CO}_{2}$ policy is only possible, in the mid term, if it does not undermine the competitiveness of a region or country. To protect competitiveness, energy-intensive sectors might be excluded from the ETS, but this would weaken the overall scheme. Alternatively, the allocation methodology of free allowances could be redesigned to reduce the impact of $\mathrm{CO}_{2}$ prices on product prices. But this would distort investment and operation incentives and severely restrict substitution effects to less carbon intensive products, seriously undermining the effectiveness of the ETS in deliver CO2 emission reductions.

Border tax adjustment may be a preferable solution to facilitate the longer term extension of $\mathrm{CO}_{2}$ policies in the absence of global agreement (Biermann and Brohm 2003). Ismer and Neuhoff (2004) suggest the following approach to address frequently voiced concerns about WTO compatibility (Esty 1994). Suppose a company producing one widget, with best available technology, emits $\mathrm{X}$ tons of $\mathrm{CO} 2$ and consumers $\mathrm{Y}$ MWh of electricity in the process. Emission trading increases costs of this company by $\mathrm{X}$ times the allowance price and $Y$ times the price increase of electricity due to emission trading. An auditing body will determine the factors $X$ and $Y$ for the best available technology of the relevant product groups, thus minimising administrative efforts (Zhang 1998). The 
auditing body would consult with industry, ensuring a balanced result between the differing interests of domestic and foreign industry. Any exporter out of the area covered by the emission-trading scheme will now be reimbursed for these costs. Older or less efficient plants will also be compensated at the level of the best available technology. On the flip side, a tariff at the level of these costs is levied on imports. This reinstates a level playing field for companies irrespective of the domestic $\mathrm{CO}_{2}$ policy.

The joint implementation of stringent $\mathrm{CO}_{2}$ trading with this type of border tax adjustment will leave companies in foreign countries weakly better off than the absence of any scheme, while domestic companies are weakly worse off. The joint implementation thus addresses concerns resulting from analysis of independent implementation of border tax adjustment (Charnovitz 2004). The joint scheme achieves the objective of facilitating unilateral internalisation of $\mathrm{CO}_{2}$ costs, as simulated for the cement sector (Demailly and Quirion (2006), without discriminating against foreign producers.

However, WTO regulations mean that companies could only be compensated for the real costs they incur as a result of the regulation - not for the marginal costs or opportunity costs that follow from free allocation. Thus, companies could only be compensated up the level of actual, average costs incurred, whereas the competitiveness issue is more to do with the impact of marginal costs of prices, at least when firms seek to maximise profits. Auctioning helps to bring average cost impacts in line with the marginal costs, and thus would enable a greater level of border tax adjustment more aligned with any actual price differentials. To implement effective BTA, a prerequisite for WTOcompatibility is auctioning.

\subsection{The feasibility of long-term price signals}

A further advantage of auctions is that they could be employed to provide the basis for a clear, long-term carbon price signal. Section 4.2 above summarised reasons why economists have tended to argue in favour of price-oriented controls; and mitigationrelated investments would be easier to plan if there were clearer expectations about carbon prices. The active use of auctions could support several avenues towards this. 
One is the direct use of the mechanisms discussed above for introducing a "price floor", coupled with announcements on the level of longer term "floors" to which this mechanism would applied. This would in particular increase investor confidence in low carbon technology investments.

It would not address the opposite risk, of prices spiralling up to unacceptable levels, but increased volumes of auctioning overall would tend to provide a far larger "cushion" between the initial cutback facing industry, and the overall volume of allowances available after auction. In principle, this could be supplemented by a genuine price ceiling - a price at which allowances would be made available for purchase without limit.

Given the potential difficulties of setting 'universal' long-term price signals, other linkages are possible, however. Helm and Hepburn (2005) propose a scheme in which national governments would auction off carbon contracts for the supply of emission reductions over a long-time horizon, such as 20-30 years. ${ }^{48}$ That is, the government would pay the private sector to reduce emissions. This would provide low-carbon innovators with a forward revenue stream with long-term price certainty which could be employed to secure project finance. ${ }^{49}$ Given the large uncertainty about future climate policy requirements, long-term contracts should be designed to ensure that governments retain the flexibility to implement more stringent climate policy if the need arises. $^{50}$

Auctions would provide the Treasury with the public funds necessary to run carbon contract auctions in advance, removing the need for the emission reductions purchased to be fungible with the EU ETS. They would also be politically palatable as spending auction revenues on long-term carbon contracts would represents genuine revenue

\footnotetext{
${ }^{48}$ A key feature of the scheme is that the auction would be technology neutral, so that the government does not have to engage in the fraught process of 'picking winners'.

49 This could lead to the development of a more sophisticated forward market for long-term allowances, in which low-carbon innovators could hedge against future low prices by taking a short position (i.e. agreeing to provide reductions).

50 Allowing for this flexibility would not erode the credibility of the contract, which is so crucial in climate policy (Helm, Hepburn and Mash, 2003). An increase in stringency in climate policy would not reduce the value of any previously signed long-term carbon contracts.
} 
recycling to industry in a manner that enhances the environmental effectiveness of the EU ETS, ${ }^{51}$ and also provides a much-needed long-term price signal.

\footnotetext{
${ }^{51}$ To get a rough sense of the potential improvement in environmental effectiveness offered by recycling auction revenues into long-term carbon contracts, consider the following highly imperfect back-of-theenvelope calculation. If $50 \%$ of a member state's emissions are covered by the EU ETS, then auctioning $10 \%$ of Phase II allowances is equivalent to auctioning 5\% of the applicable Kyoto limit. Now suppose the prices paid in the auction are similar to the prices the government pays for emission reductions delivered under the carbon contract. If the carbon contracts required delivery for 2008-2012, the government would thereby achieve an additional 5\% reduction in emissions. Of course, the point of a long-term carbon contract is to extend beyond 2012, so they would deliver less than a 5\% reduction over the first commitment period, but would also deliver emissions reductions after 2012. The net present value of the emissions reductions delivered should be within an order of magnitude of a $5 \%$ reduction in the first commitment period.
} 


\section{Conclusion}

The traditional arguments for and against auctioning, reviewed in section 2, support two widely-known conclusions, namely that (i) auctions are almost certainly in the public interest, but (ii) political economy considerations have to date presented serious obstacles to the implementation of auctioning within the EU ETS on any significant scale. The winds may be changing, however, and more recent signs are that governments are keen to find approaches to resolve these political challenges.

If auctions are employed in Phase II, section 3 of this paper provides some broad guidance on how this might occur. Sealed-bid auctions are likely to be appropriate, and both discriminatory and uniform-price payment rules are feasible. Auctions could be conducted at relatively frequent intervals (every six months or so) over the 2008-2012 commitment period. Market power is not expected to be a significant problem as long as Member States do not impose artificial restrictions on entry.

Perhaps the most interesting possibilities for auctions, though, go beyond the usual benefits of static and dynamic efficiency. Section 4 discussed the potential for auctions (and the resulting revenues) to provide several new benefits, including (i) an increase the environmental effectiveness by focussing management attention on carbon; (ii) an amelioration of competitiveness considerations, either by direct support or by legitimising border-tax adjustments; (iii) a clearer long-term price signal, through recycling the revenues into carbon contracts; and (iv) an improvement to price stability if Member States agree to coordinate auctions by including an auction price floor.

One can only speculate whether these additional considerations will increase the political support for greater use of auctioning in Phase II. Certainly, as targets become more demanding, efficiency becomes more and more important and the appeal of auctioning will correspondingly increase. The creative deployment of auctions to increase efficiency and reduce political and competitiveness issues would be feasible, and would yield enormous social benefits. 


\section{References}

Aldy, J.E., Orszag, P. R. and Stiglitz, J. E. 2001. Climate change: an agenda for global collective action. Conference on "The timing of climate change policies", Pew Center on Global Climate Change, October.

Archibald, C. and Malvey, P. F. 1998. Uniform-Price Auctions: Update of the Treasury Experience. United States Treasury Working Paper.

Ausubel, L. M. and Cramton, P. 1998. Auctioning Securities. University of Maryland Working Paper.

Ausubel, L. M. and Cramton, P. 2002. Demand Reduction and Inefficiency in Multi-Unit Auctions. University of Maryland Working Paper.

Baldursson, F. M. and von der Fehr, N.-H. M. 2004. Price volatility and risk exposure: on market-based environmental policy instruments. Journal of Environmental Economics and Management, 48, 682-704.

Biermann, F. and R. Brohm 2003. Implementing the Kyoto Protocol without the United States: The Strategic Role of Energy Tax Adjustments at the Border. (5).

Bovenberg, A. L. and Goulder, L. H. 1996. Optimal environmental taxation in the presence of other taxes: general-equilibrium analyses. American Economic Review 86:4, 985-1000.

Bovenberg, A. L. and de Mooij, R. A. 1994. Environmental levies and distortionary taxation. American Economic Review 84:4, 1085-1089. 
Bovenberg, A. L. and de Mooij, R. A. 1997. Environmental levies and distortionary taxation: reply. American Economic Review 87:1, 252-253.

Bovenberg, A.L. and van der Ploeg, F. 1994. Environmental policy, public finance and the labour market in a second-best world, Journal of Public Economics, 55, 349-390.

Charnovitz, S. (2004). Trade and Climate: Potential Conflicts and Synergies. Beyond Kyoto: Advancing the international effort against climate change, PEW Center on Global Climate Change.

Cramton, P. and Kerr, S. 2002. Tradable Carbon Permit Auctions: How and why to auction not grandfather. Energy Policy, 30, 333-345.

Demailly, D. and P. Quirion (2006) Leakage from climate policies and border tax adjustment: Lessons from a geographic model of the cement industry.

Department of Trade and Industry, 2005. EU ETS: Planning for auction or sale. Prepared by Environmental Resource Management (ERM) and Market Design Inc. (MDI), August 2005.

Diamond, P. A. and Mirrlees, J. A. 1971. Optimal taxation and public production I: Production efficiency and II: Tax rules, American Economic Review, 61, 8-27 and 261-78.

Esty, D. C. (1994). Greening the GATT - Trade, Environment and the Future. Washington/D.C, Institute for International Economics.

Freixas, X., Guesnerie, R. and Tirole, J. 1985. Planning under incomplete information and the ratchet effect, Review of Economic Studies, 52:2, 173-191. 
Fullerton, D. 1997. Environmental levies and distortionary taxation: reply. American Economic Review 87:1, 245-251.

Fullerton, D. and Metcalf, G. 2001. Environmental controls, scarcity rents, and preexisting distortions, Journal of Public Economics, 80, 249-68.

Gigerenzer, G. 2003. Fast and Frugal Heuristics: The Tools of Bounded Rationality. In Koehler, D. and Harvey, N. (eds.), Handbook of Judgment and Decision Making, Oxford, UK: Blackwell.

Gigerenzer, G. and Goldstein, D. G. 1996. Reasoning the fast and frugal way: models of bounded rationality. Psychological Review, 103, 650-669.

Goulder, L. H. 1995. Environmental Taxation and the Double Dividend: A Readers' Guide. International Tax and Public Finance 2, 157-183.

Goulder, L. H. Parry, I. W. H. and Burtraw, D. 1997. Revenue-raising vs other approaches to environmental protection: the critical significance of pre-existing tax distortions, RAND Journal of Economics, 28, 708-31.

Goulder, L. H., Williams, R.C. and Burtraw, D. 1999. The cost-effectiveness of alternative instruments for environmental protection in a second-best setting, Journal of Public Economics, 72, 329-60.

Hammar, H. and Jagers, S. C., 2006. Can Trust in Politicians Explain Individuals' Support for Climate Policy? The Case of $\mathrm{CO}_{2}$ Tax, Climate Policy 5:6, 611-623.

Helm, D. 2005. Economic instruments and environmental policy. Economic and Social Review, 36:3, 205-228. 
Helm, D., Hepburn, C. and Mash, R. 2003. Credible carbon policy. Oxford Review of Economic Policy, 19:3, 438-50.

Helm, D. and Hepburn, C. 2005. Carbon contracts and energy policy: an outline proposal, Oxford University mimeo, October.

Hepburn, C. 2006. Regulation by prices, quantities or both: a review of instrument choice. Oxford Review of Economic Policy, 22:2, forthcoming.

Hepburn, C., Quah, J. K.-H. and Ritz, R. A. forthcoming. On emissions trading and firm profits. Oxford University Department of Economics Discussion Paper.

Hoel, M. and Karp, L. 2001. Taxes and quotas for a stock pollutant with multiplicative uncertainty. Journal of Public Economics, 82: 91-114.

Hoel, M. and Karp, L. 2002. Taxes versus quotas for a stock pollutant. Resource and Energy Economics, 24: 367-384.

IPCC, 2001. Climate Change 2001: Mitigation. Cambridge, UK: Cambridge University Press.

Ismer, R. and K. Neuhoff (2004). Border tax adjustments : a feasible way to address nonparticipation in emission trading. Cambridge working papers in economics; CWPE 0409. Cambridge, CMI Electricity Project Department of Applied Economics.

Jacoby, H. D. and Ellerman, A. D. 2004. The safety valve and climate policy. Energy Policy 32, 481-491.

Johnston, A. (2006). "Free allocation of allowances under the EU Emissions Trading System - legal issues." Climate Policy(Special Issue: Emissions allocation, 
incentives and industrial competitiveness under the EU Emissions Trading Scheme, forthcoming).

Klemperer, P. D. 2004. Auctions: theory and practice. Princeton: Princeton University Press.

Klemperer, P. D. et al. forthcoming. Auctions for Environmental Improvements: the UK ETS Auction. Nuffield College Working Paper.

de Leyva, E. and Lekander, P. A. 2003. Climate change for Europe's utilities. McKinsey Quarterly, 1, 120-131.

McKibbin, W. J. and Wilcoxen, P. J. 2002. The role of economics in climate change policy, Journal of Economic Perspectives, 16:2, 107-129.

McLean, B. J. 1997. Evolution of Marketable Permits: The U.S. Experience With Sulfur Dioxide Allowance Trading. International Journal of Environmental and Pollution, $8: 1 / 2,19-36$.

Neuhoff, K., K. Keats, et al. (2006). "Allocation, incentives and distortions: the impact of EU ETS emissions allowance allocations to the electricity sector." Climate Policy(Special Issue: Emissions allocation, incentives and industrial competitiveness under the EU Emissions Trading Scheme, forthcoming).

Parry, I. W. H. 1995. Pollution Taxes and Revenue Recycling, Journal of Environmental Economics and Management, 29, S64-S77.

Parry, I. W. H. 2003. Fiscal interactions and the case for carbon taxes over grandfathered carbon permits, Oxford Review of Economic Policy, 19:3, 385-399.

Parry, I. W. H., Williams, R. C. and Goulder, L. H. 1999. When can carbon abatement policies increase welfare? The fundamental role of distorted factor markets, Journal of Environmental Economics and Management, 37, 52-84. 
Pigou, A. C. 1920. The economics of welfare. London: McMillan \& Co.

Pizer, W. A. 1997. Prices vs. Quantities Revisited: the case of climate change, RFF Discussion Paper 98-02, Resources for the Future, Washington DC.

Pizer, W. A. 2002. Combining price and quantity controls to mitigate global climate change, Journal of Public Economics, 85, 409-434.

Roberts, M. J. and Spence, M. 1976. Effluent charges and licences under uncertainty. Journal of Public Economics, 5, 193-208.

Smale, R., H. M, et al. (2006). "The impact of CO2 emissions trading on firm profits and market prices." Climate Policy(Special Issue: Emissions allocation, incentives and industrial competitiveness under the EU Emissions Trading Scheme, forthcoming).

Weitzman, M. 1974. Prices vs. Quantities. Review of Economic Studies, 41:4, 477-491.

Zhang, Z. X. (1998) Greenhouse Gas Emissions Trading and the World Trading System. Journal of World Trade 32(5): P.219-239. 